\title{
Debatedor
}

\section{O capitalismo contemporâneo e a saúde do trabalhador}

\section{Contemporary capitalism and worker's health}

José Dari Krein ${ }^{1}$

O instigante artigo de Costa, Lacaz, Jackson Filho e Vilela (2013) tem como eixo algo absolutamente importante, que é relacionar a saúde e a segurança com as condições de trabalho proporcionadas pela dinâmica do capitalismo contemporâneo e as disputas sobre os rumos das políticas públicas no país. $\mathrm{O}$ artigo suscitou-me duas reflexões principais. A primeira é de caracterizar o ambiente desfavorável ao trabalho no capitalismo contemporâneo como uma questão que está na origem, no nosso ponto de vista, das transformações das condições de saúde dos que vivem do trabalho. A segunda é a relação entre economia e segurança e saúde dos trabalhadores, em que o desenvolvimento econômico é um pressuposto, mas precisa vir acompanhado de regulamentações e políticas públicas para garantir um ambiente de trabalho em que a dignidade do trabalhador seja respeitada.

Dois acontecimentos recentes em Bangladesh revelam com clareza a face do capitalismo contemporâneo e os seus reflexos sobre a situação do trabalho e da saúde de quem precisa labutar para conseguir sobreviver. O primeiro fato refere-se à queda de um prédio de indústria têxtil, em 24 de abril de 2013, em que mais de mil trabalhadores e trabalhadoras perderam a vida. As fotos são chocantes, relevando um ambiente de destruição e mortes ao lado de importantes marcas da indústria mundial da moda. É uma situação que combina condições de trabalho extremamente precárias com a produção de bens consumidos em todos os cantos do mundo por aqueles que têm renda. O segundo é uma manifestação - duramente reprimida - de trabalhadores/as têxteis também em Bangladesch, em 20 de maio deste mesmo ano, reivindicando uma elevação do piso salarial dos atuais trinta e oito dólares para cem dólares mensais². Também poderíamos citar o caso do estagiário/eco-

\footnotetext{
${ }^{1}$ Centro de Estudos Sindicais e de Economia do Trabalho, Instituto de Economia da Universidade Estadual de Campinas. Campinas, SP, Brasil. E-mail: dari@eco.unicamp.br

${ }^{2}$ Fonte: http://oglobo.globo.com/economia/trabalhadores-do-setor-textil-protestam-por-salario-minimo-de-us-100-em-bangladesh-10108146. Acesso em: 10 dez. 2013.
} 
nomista (Moritz Erhardt) que, em agosto de 2013, faleceu em Londres depois de trabalhar 72 horas consecutivas no Bank of America com o sonho de ser efetivado pela empresa. São fatos que evidenciam de forma escancarada as características do atual processo de globalização financeira ${ }^{3}$, de internacionalização da produção de bens e servi$\operatorname{ços}^{4}$ e de redefinição do papel do Estado ${ }^{5}$, sob o domínio do neoliberalismo, que busca a redução de custos, a ampliação da liberdade de ação do capital. Essas três características são implementadas diferentemente em cada Estado nacional, dependendo das resistências de forças sociais e políticas. Os fatos citados expressam de forma cristalina a lógica de como os negócios se organizam, buscando viabilizar a produção com baixos custos em locais sem tradição sindical, sem proteção social e com uma condição de vida muito rebaixada, o que permite ao capital pagar salários muito baixos e oferecer precárias condições de trabalho. Também é bom lembrar que muitos consumidores acabam aceitando essa lógica, pois podem comprar produtos com preços menores. Enfim, não é possível discutir a questão da saúde deslocada do que ocorre na economia, na forma de organização da produção de bens e serviços e no quadro regulatório existente no capitalismo contemporâneo e no Brasil, em particular.

Assim, a questão a ser destacada é que as características do capitalismo contemporâneo são desfavoráveis aos trabalhadores e à sua capacidade de ação coletiva, que apresenta como alternativa ao trabalho a flexibilização de direitos (redução) e a diminuição da proteção social. A fragilização das instituições de representação coletiva colocam problemas adicionais na perspectiva de garantir melhores condições de trabalho e melhor distribuição dos rendimentos do trabalho. Faux ${ }^{6}$, em um estudo destas duas variáveis ao longo dos últimos 60 anos, nos Estados Unidos, mostra que existe uma estreita correlação entre a taxa de sindicalização e a desigualdade social. A desigualdade é maior quando é menor a taxa de sindicalização.
O segundo aspecto a ser destacado é a relação entre economia e desenvolvimento econômico e as questões de segurança e saúde do trabalhador. O Brasil ainda é um país de renda média para pobre, no contexto internacional, o que coloca a necessidade de continuar crescendo não somente para aumentar a renda, mas para criar condições para a estruturação da proteção social e para a luta por melhorias no ambiente de trabalho. Dois exemplos: um dos problemas de efetivação, entre outros, da implementação das políticas de proteção social definidas na Constituição de 1988 foi a não solução da questão econômica, que abriu espaço para um período de hegemonia neoliberal. Isso implicou concretamente na opção política do país de se inserir na chamada globalização financeira de forma passiva, com graves consequências para a estruturação do mercado de trabalho e o rumo das políticas públicas. Esses foram aspectos decisivos para discutir as bases de definição e implementação das políticas públicas em geral e em particular na área de segurança e saúde do trabalhador. O segundo exemplo: o Brasil apresenta um gasto proporcional do PIB com Saúde similar ao de alguns países desenvolvidos, tais como a Alemanha, o Japão e a Dinamarca, e também de nações muito pobres, como Nicarágua e Gana. O que importa não é o percentual do PIB, mas o gasto per capita. Em relação ao percentual do PIB, o Brasil fica em uma posição intermediária, mas na comparação com o valor per capita, o gasto em saúde se localiza em uma posição muito ruim.

Diante disso, duas questões precisam ser consideradas. A primeira, a melhora na qualidade da saúde, incluindo a do trabalhador, também passa pelo aumento da renda per capita do país, o que significa ter um crescimento sustentável da economia dentro de um projeto de desenvolvimento com equidade e inclusão social, inclusive que não privilegie somente o consumo individual, mas fortaleça o setor público, tais como a educação e a saúde. A segunda, um maior nível de desenvolvimento é facilitador para lutar pela melhoria das condições de trabalho, especialmente com o au-

\footnotetext{
${ }^{3}$ Por globalização financeira compreende-se o movimento que torna a especulação financeira como referência de valorização do capital e que impõe um processo brutal de racionalização do trabalho, tal como a terceirização.

${ }^{4}$ Internacionalização significa a liberdade para os grandes grupos econômicos organizarem os seus negócios em escala mundial, atuando em rede e aproveitando as vantagens comparativas de cada local para viabilizar a produção de bens e serviços. O que implica ter abertura econômica, liberdade de movimento de capitais. Esse processo coloca uma espada sobre a cabeça dos trabalhadores para que aceitem certas condições ou os investimentos que viabilizam a unidade serão transferidos para outras localidades. É um instrumento muito forte de pressão para reduzir direitos. ${ }^{5}$ É um Estado cada vez mais a serviço da proteção dos negócios privados, mercantilizando a sua prestação de serviços e desconstruindo a proteção social.

${ }^{6}$ Jeff Faux, do Economic Policy Institute, em conferência proferida no Centro de Estudos Sindicais e de Economia do Trabalho (Cesit)/Instituto de Economia da Unicamp, em 2 de maio de 2013, abordando tema do livro de sua autoria: The servant economy: where America's elite is sending the middle class? Hoboken, NJ, USA: John Wiley \& Sons, 2012.
} 
mento do emprego, o que tende a elevar o poder de resistência e de barganha dos trabalhadores para enfrentar certas situações. Portanto, o que chamo a atenção é que não são somente as hodiernas formas de organização da produção e do trabalho que tendem a criar um ambiente mais racionalizado, flexível e desfavorável ao trabalho, mas também a existência de um mercado de trabalho pouco estruturado, com alta informalidade e muitas atividades de baixa produtividade, sendo decisivo para termos um ambiente de trabalho com condições muito ruins. Esse é um dos aspectos importantes que colocam o Brasil "em situação crítica quando comparado com nações socialmente mais desenvolvidas" nos indicadores relativos à saúde dos trabalhadores (COSTA; LACAZ; JACKSON FILHO; VILELA, 2013, p. 12).

Para além da questão do emprego em si, se temos como perspectiva um ambiente de trabalho mais saudável, também é fundamental considerarmos a forma como o país está impulsionando a sua economia, pois ela define as características das ocupações a serem geradas. Por exemplo, um modelo de desenvolvimento que privilegia o agronegócio tende a criar ocupações que exigem baixa qualificação, portanto, com baixos salários e piores condições de trabalho. Neste sentido, a definição das condições de trabalho passa pelo modelo de desenvolvimento que está sendo implantado no país, pois ele define que tipo de ocupação pode ser gerada. Assim, os rumos do desenvolvimento também são um objeto de disputa. Nessa perspectiva, ele precisa ser capaz de alavancar um sistema de produção de bens e serviços mais sofisticado tecnologicamente (incluindo a indústria) e voltado para o atendimento das necessidades do país, tanto em termos de infraestrutura social (saúde, educação etc.), como física (energia, transporte, telecomunicações etc.).

A constituição de um modelo de desenvolvimento não passa simplesmente por atender as de-

\section{Referências}

COSTA, D.; LACAZ, F. A. C.; JACKSON FILHO, J. M.; VILELA, R. A. G. Saúde do Trabalhador no SUS: desafios para uma política pública. Revista Brasileira de Saúde Ocupacional, São Paulo, v. 38, n. 127, p. 11-30, 2013. mandas do mercado, as exigências do setor privado, apesar de seu poder de pressão ser muito forte. Portanto, as possibilidades de intervenção para melhoria do ambiente de trabalho e reversão dos péssimos indicadores de saúde e segurança começam na definição do modelo de desenvolvimento, mas não se esgotam nele. O crescimento é um pressuposto que necessita vir acompanhado de regulamentações e políticas públicas, aspectos que também são disputados na sociedade, o que pressupõe criar condições para o Estado intervir, no sentido de eliminar os efeitos causadores dos problemas de segurança e saúde do trabalhador que têm relação com o tipo de ocupação criada e a forma como é organizada a produção de bens e serviços.

Importante ressaltar que, nessa disputa, historicamente, um aliado importante é o movimento sindical, subsidiado por pesquisadores que procuram identificar a causa dos problemas e formuladores e executores de políticas públicas que não se limitam a atuar sobre o fato consumado (a doença, o acidente), mas procuram intervir para melhorar o ambiente de trabalho como condição para enfrentar o problema da saúde e segurança no trabalho, como é a perspectiva dos autores do artigo.

A perspectiva de intervir no ambiente de trabalho não será dada pela dinâmica capitalista, mas pela existência de atores sociais e de insitutições públicas que têm a função de estabelecer um contraponto na perspectiva de assegurar a dignidade de quem precisa vender a sua força de trabalho para sobreviver. Nesse sentido, as ações que possam fortalecer os espaços de intervenção são fundamentais, especialmente em um momento em que as transformações no capitalismo contemporâneo buscam fragilizar os sindicatos e as instituições públicas, o que permite ao capital organizar o trabalho a sua favor, prejudicando a saúde e a segurança dos trabalhadores.

Recebido: 02/10/2013

Aprovado: 09/10/2013 